University of Nebraska - Lincoln

DigitalCommons@University of Nebraska - Lincoln

Biological Systems Engineering: Papers and

Publications

Biological Systems Engineering

2004

\title{
Policosanol Contents and Composition of Grain Sorghum Kernels and Dried Distillers Grains
}

\author{
Keum T. Hwang \\ Chonbuk National University \\ Curtis L. Weller \\ University of Nebraska-Lincoln, cweller1@unl.edu \\ Susan L. Cuppett \\ University of Nebraska-Lincoln, scuppett1@unl.edu \\ Milford Hanna \\ University of Nebraska-Lincoln, mhanna1@unl.edu
}

Follow this and additional works at: https://digitalcommons.unl.edu/biosysengfacpub

Part of the Biological Engineering Commons

\footnotetext{
Hwang, Keum T.; Weller, Curtis L.; Cuppett, Susan L.; and Hanna, Milford, "Policosanol Contents and Composition of Grain Sorghum Kernels and Dried Distillers Grains" (2004). Biological Systems Engineering: Papers and Publications. 108.

https://digitalcommons.unl.edu/biosysengfacpub/108
}

This Article is brought to you for free and open access by the Biological Systems Engineering at DigitalCommons@University of Nebraska - Lincoln. It has been accepted for inclusion in Biological Systems Engineering: Papers and Publications by an authorized administrator of DigitalCommons@University of Nebraska Lincoln. 


\title{
Policosanol Contents and Composition of Grain Sorghum Kernels and Dried Distillers Grains
}

\author{
Keum T. Hwang, ${ }^{1}$ Curtis L. Weller, ${ }^{2.3}$ Susan L. Cuppett, ${ }^{4}$ and Milford A. Hanna ${ }^{5}$
}

ABSTRACT

Cereal Chem. 81(3):345-349

Grain sorghum can be a major source of policosanols, long-chained alcohols, that have beneficial physiological activities. Sorghum dried distillers grains (DDG), a by-product of ethanol production from grain sorghum, contain a large amount of policosanols. Content and composition of policosanols in long-chained lipids extracted from grain sorghum kernels and DDG were determined. Long-chained lipids were extracted using hot hexane or hot ethanol. The major components of the long-chained lipids extracted from grain sorghum kernels, as determined using HPLC, were policosanols $(37-44 \%)$, aldehydes $(44-55 \%)$, and acids $(4-5 \%)$. Long-chained lipids from DDG contained $52 \%$ policosanols, $23 \%$ aldehydes, $6.4 \%$ acids, and $17 \%$ wax esters/steryl esters. Composition of policosanols in DDG matched the composition in grain sorghum kernels, as determined by gas chromatography, even though the content of policosanols in DDG was greater than the content in grain sorghum kernels. Policosonal composition ranges were 0-1\% C22:0, 0-3\% C24:0, 6-8\% C26:0, 1\% C27:0, 43-47\% C28:0, 1-2\% C29:0, $40-43 \% \mathrm{C} 30: 0$. and $1-4 \% \mathrm{C} 32: 0$.
A considerable amount of wax-like material $(\approx 0.2 \%, \mathrm{w} / \mathrm{w}, \mathrm{db})$ can be extracted from whole kernels of grain sorghum (Weller et al 2000). The chemical composition of this material has been reported sporadically and without consensus over the last half century (Bunger and Kummerow 1951; Cannon and Kummerow 1957; Dalton and Mitchell 1959; Bianchi et al 1979; Avato et al 1990; Seitz 1997). Recently, Hwang et al (2002a) confirmed that the major components of the wax-like material were long-chained aldehydes, alcohols, and acids. Bianchi et al (1979) and Avato et al (1990) previously reported that these components were mainly saturated 28- and 30-carbon compounds. Only a small amount of wax esters, a traditional wax component, was contained in the wax-like material. Therefore, long-chained lipids may describe the material more appropriately.

Annual production of grain sorghum in the United States is 10 20 million metric tons. About $12 \%$ of the grain sorghum produced in the United States is used for ethanol production (Stan Fury, National Grain Sorghum Producers Director, personal communication). One of the by-products from the ethanol production is dried distillers grains (DDG). Sorghum DDG, in which little, if any, starch remains after ethanol production, still contains lipid and lipidrelated materials. It is assumed long-chained lipids are a part of the lipid materials; however, their presence has never been reported.

Policosanols are a mixture of primary long-chained alcohols and are commercially available as nutritional supplements containing mostly octacosanol (28:0), triacontanol (30:0), hexacosanol (26:0), and dotriacontanol (32:0). They have been produced from sugar cane, beeswax, and cereal germs. The alcohols in the long-chained lipids extracted from grain sorghum discussed above are also policosanols. Policosanols reportedly have physiological activities such as improving lipid levels in the blood (Aruzazabala et al 1994; Kato et al 1995; Gouni-Berthold and Berthold 2002), reducing platelet aggregation (Aruzazabala et al 1996), improving exercise performance of coronary heart disease patients (Stüsser et al 1998), and increasing muscle endurance (Kabir and Kimura 1995).

'Dept. of Food Science and Human Nutrition. and Institute for Molecular Biology and Genetics, Chonbuk National University, Jeonju. Jeonbuk, 561-756. Korea.

2 Department of Biological Systems Engineering. University of Nebraska, Lincoln, NE 68583-0726.

${ }^{3}$ Corresponding author. Phone: 402-472-9337. Fax: 402-472-6338. E-mail: cweller 1 @unl.edu

${ }^{4}$ Department of Food Science and Technology, University of Nebraska. Lincoln, NE 68583-0919.

${ }^{5}$ Industrial Agricultural Products Center. University of Nebraska, Lincoln, NE 68583-0730.

Publication no. C-2004-0324-01R

(C) 2004 American Association of Cereal Chemists, Inc.
Stewart and Downing (1981) pioneered an HPLC method for the separation of wax esters and steryl esters in human skin surface wax. Nordbäck and Lundberg (1999) also successfully separated steryl esters from wax esters in wax from a zooplankton sample using an HPLC system. To our knowledge, the entire composition of a wax using HPLC had not been reported before Hwang et al (2002b) developed an HPLC method to analyze the composition of the major components in carnauba and sorghum waxes. Components of the long-chained lipids extracted from grain sorghum were analyzed by this HPLC method and $\approx 40 \%$ of the longchained lipids were policosanols (Hwang et al 2002b).

The objectives of this study were to determine and compare yield and composition of long-chained lipids extracted from grain sorghum kernels and DDG, and to determine the content and composition of policosanols in the long-chained lipids.

\section{MATERIALS AND METHODS}

\section{Grain Sorghum Kernels and DDG}

Grain sorghum kernels were Golden Harvest H512 (harvested in 1999), Warner W902W FG (harvested in 1999 and 2000), Producers (harvested in 1999), and PH77FG (harvested in 2000). All were grown in Nebraska. Sorghum DDG from ethanol production using mixed commercial grain sorghum hybrids was obtained from a production run at U.S. Energy Partners (Russell, KS) in April 2002.

\section{Extraction of Long-Chained Lipids}

Extraction of long-chained lipids from whole kernels of grain sorghum followed the method of Hwang et al (2002a). Grain sorghum kernels were washed with tap water and dried at $45^{\circ} \mathrm{C}$ over $24 \mathrm{hr}$. The grain sorghum ( $800 \mathrm{~g}$ at $\approx 10 \%$, wb, moisture) with $800 \mathrm{~mL}$ of hexane or ethanol was refluxed for $30 \mathrm{~min}$. The mixture was filtered through a coffee filter paper lying on top of a Whatman No. 2 filter paper (Whatman, Maidstone, Kent, UK). The filtrate was placed in a freezer at $-18^{\circ} \mathrm{C}$ for at least $8 \mathrm{hr}$. Filtering the cold miscella onto Whatman No. 42 filter paper, which was then desolvented under vacuum, collected the precipitate of the long-chained lipids.

Extraction of long-chained lipids from DDG was done in the same way as for grain sorghum kernels except that the DDG sample was not washed before extraction and that $400 \mathrm{~g}$ of DDG (at $\approx 10 \%$, wb, moisture) and $600 \mathrm{~mL}$ of hexane were used for the extraction. For half of the DDG sample, the precipitate of longchained lipids, collected on Whatman No. 42 filter paper, received an additional rinse with $\approx 30 \mathrm{~mL}$ of hexane at room temperature to remove any compounds soluble at room temperature. Yield of 
long-chained lipids \% db) was then calculated as $W / S /(100-M) \times$ 100 , where $W$ is total desolvented long-chained lipid mass $(\mathrm{g})$ collected on filter papers, and $S$ is sorghum or DDG mass used for extraction $(\mathrm{g}) ; M$ is moisture content of sorghum or DDG (\% wb).

\section{Policosanol Content in Long-Chained Lipids}

Policosanol content along with contents of major components in the long-chained lipids extracted from grain sorghum kernels and DDG were determined using HPLC as in Hwang et al (2002b). Two 510 HPLC pumps (Waters Corp., Milford, MA) were operated in gradient modes as in Table I (gradients I and II). Flow rate of mobile phase was $1 \mathrm{~mL} / \mathrm{min}$. Column was a Luna $5-\mu \mathrm{m}$ silica column ( $250 \mathrm{~mm} \mathrm{~L} \times 4.6 \mathrm{~mm}$ i.d.) (Phenomenex, Torrance, CA) connected to a guard column $(4 \mathrm{~mm} \mathrm{~L} \times 3 \mathrm{~mm}$ i.d. silica cartridge in a SecurityGuard cartridge system (Phenomenex). The column and guard column were heated at $40^{\circ} \mathrm{C}$ using a Waters column heater module. Exposed lines from injection loop to detector connection were maintained at $\approx 38-40^{\circ} \mathrm{C}$ using a wrapped heating tape. Detector was a Varex ELSD II (Rockville, MD) operated at $50^{\circ} \mathrm{C}$ with nitrogen pressure of $930 \mathrm{kPa}$. Samples were dissolved in hexane at $20 \mu \mathrm{g} / 100 \mu \mathrm{L}$ and $100 \mu \mathrm{L}$ of each was injected. By injecting standards (aldehyde fraction for aldehydes; lignoceryl alcohol for alcohols; lignoceric acid for acids; $n$-octacosane for hydrocarbons; trilinolenin for triacylglycerols; and behenyl behenate for wax esters) with different concentrations covering the levels of sample components for each HPLC system, relationships between concentration and area were plotted for calibration, which was then used for calculation of the component levels in the long-chained lipids.

\section{Policosanol Composition in Long-Chained Lipids}

Policosanol fractions ( $2 \mathrm{~mL}$ ) from $20 \mu \mathrm{g}$ of long-chained lipids, which were dissolved in $100 \mu \mathrm{L}$ of hexane and injected into HPLC operated with gradient II system, were collected by disconnecting the tubing to the detector at the appropriate time and eluting directly from the HPLC column into a vial. The solvent was evaporated from the fraction in the vial under a nitrogen stream using a temperature $<40^{\circ} \mathrm{C}$. Compositions of policosanols were determined using gas chromatography (GC) with a minor modification of the González-Canavaciolo and Magraner-Hernández (1999) method. To the desolvented policosanol fraction, $0.2 \mathrm{~mL}$ of chloroform and $0.05 \mathrm{~mL}$ of $\mathrm{N}$-methyl- $\mathrm{N}$-(trimethylsilyl)trifluoroacetamide (Sigma Chemical, St. Louis, MO) were added. The contents were heated at $60^{\circ} \mathrm{C}$ for $10 \mathrm{~min}$ to make trimethylsilyl (TMS) ether derivatives. A standard mixture of palmityl alcohol, stearyl alcohol, eicosanol, behenyl alcohol, tricosanol, lignoceryl alcohol, hexacosanol, heptacosanol, octacosanol, and triacontanol (purchased from Nu-Chek Prep, Inc., Elysian, MN) containing 1-8 $\mu \mathrm{g}$ of each in $0.2 \mathrm{~mL}$ of chloroform was prepared and derivatized in the same manner as above for identifying the retention times of the alcohols and for cal- culating their response factors. The TMS ether derivative solution $(2 \mu \mathrm{L})$ was injected into a gas chromatograph (HP 6890, HewlettPackard, Wilmington, DE) equipped with a DB-5 column $(30 \mathrm{~m}$, $0.25 \mathrm{~mm}$, i.d. and $0.25 \mu \mathrm{m}$, film thickness) (J\&W Scientific, Folsom, CA) and using helium as the carrier gas. The injector was initially in a pulsed splitless mode, which shifted to a split mode (ratio 100:1) after $1.5 \mathrm{~min}$; the detector was a flame-ionization detector. Injector and detector temperatures were both set at $315^{\circ} \mathrm{C}$. Oven temperature was programmed to start and hold at $150^{\circ} \mathrm{C}$ for $1 \mathrm{~min}$ before increasing to $210^{\circ} \mathrm{C}$ at $20^{\circ} \mathrm{C} / \mathrm{min}$, increasing to $310^{\circ} \mathrm{C}$ at $4^{\circ} \mathrm{C} / \mathrm{min}$, holding at $310^{\circ} \mathrm{C}$ for $1 \mathrm{~min}$, increasing to $315^{\circ} \mathrm{C}$ at $25^{\circ} \mathrm{C} / \mathrm{min}$, and finally holding for $5 \mathrm{~min}$.

\section{RESULTS AND DISCUSSION}

Yields of long-chained lipids from the grain sorghum kernels were $0.2-0.3 \%(\mathrm{w} / \mathrm{w}, \mathrm{db})$ (Table II). This range of yields is consistent with the $0.16-0.31 \%$ range of yields observed by Weller et al (2000) for 86 commercial hybrids grown in Nebraska over five years. The yields from Golden Harvest H512 showed no difference between hexane and ethanol extractions, although appearances of the hexane- and ethanol-extracted long-chained lipids were apparently different. Differences between hexane- and ethanol-extracted long-chained lipids were discussed in detail in previous reports (Weller et al 2000; Hwang et al 2002a). PH77FG and Warner W902W FG, harvested in 2000, had greater yields of the longchained lipids $(0.30$ and $0.28 \%$, respectively) than the other sorghum kernels evaluated. Lipid yields from DDG, using the same method as that for grain sorghum kernels, were $\approx 0.6 \%$. Yields for lipids recovered from DDG, including rinsing of the cold-filtered precipitate with hexane at room temperature were $\approx 0.5 \%$.

The high yield of long-chained lipids from DDG implies that a large amount of long-chained lipids remains intact during the ethanol production process, and indicated that DDG may be a good source for production of long-chained lipids and that the lipids are concentrated in the process of ethanol production.

Conversion of starch to ethanol and carbon dioxide during ethanol production theoretically concentrates nonstarch components three times. For example, for every $3 \mathrm{~kg}$ of lipid and $9 \mathrm{~kg}$ of protein in $100 \mathrm{~kg}$ of whole kernels entering an ethanol production process, $\approx 9 \mathrm{~kg}$ of lipid and $27 \mathrm{~kg}$ of protein would be expected in every $100 \mathrm{~kg}$ of DDG.

The extent of concentration may not have reached three times due to minor losses during the various processes used in ethanol production or due to differences in the initial contents of longchained lipids in the known commercial hybrids of this study and the unspecified commercial hybrids used in Russell, KS. Further study tracking levels of grain sorghum kernel components, specifically lipid components, during ethanol production processes is warranted.

TABLE I

HPLC Gradient Mobile Systems for Analysis of Grain Sorghum Wax $x^{a, b}$

\begin{tabular}{|c|c|c|c|c|c|}
\hline \multicolumn{3}{|c|}{ Gradient I } & \multicolumn{3}{|c|}{ Gradient II } \\
\hline \multirow[b]{2}{*}{ Time (min) } & \multicolumn{2}{|c|}{ Solvent } & \multirow[b]{2}{*}{ Time (min) } & \multicolumn{2}{|c|}{ Solvent } \\
\hline & $\mathrm{A}(\%)$ & $\mathbf{B}(\%)$ & & $\mathrm{C}(\%)$ & B $(\%)$ \\
\hline 0 & 100 & 0 & 0 & 100 & 0 \\
\hline 7 & 100 & 0 & 2 & 100 & 0 \\
\hline 9 & 95 & 5 & 3 & 95 & 5 \\
\hline 14 & 95 & 5 & 10 & 95 & 5 \\
\hline 16 & 75 & 25 & 14 & 55 & 45 \\
\hline 20 & 75 & 25 & 15 & 45 & 55 \\
\hline 24 & 40 & 60 & 23 & 0 & 100 \\
\hline 28 & 40 & 60 & 26 & 0 & 100 \\
\hline 29 & 100 & 0 & 27 & 100 & 0 \\
\hline 85 & 100 & 0 & 40 & 100 & 0 \\
\hline
\end{tabular}

"Solvents: A, $0.2 \%(\mathrm{v} / \mathrm{v})$ acetic acid and $0.02 \%$ methyl tert-butyl ether (MTBE) in hexane; B, $0.2 \%(\mathrm{v} / \mathrm{v})$ acetic acid in MTBE; C, hexane.

${ }^{b}$ Flow rate was $1 \mathrm{~mL} / \mathrm{min}$. Ratio changes of the two solvents were linear. 
Heating the whole kernels in hexane extracted the long-chained lipids, which were mainly on the surface of the kernels. However, other lipid materials in DDG were likely extracted into the hexane along with long-chained lipids because inner parts of kernel were exposed to the solvent. Accordingly, some of the lipids in DDG precipitated in the hexane solution at a freezing temperature and were retained on the filter paper with the long-chained lipids. These lipids were rinsed off readily with hexane at room temperature.

The major components of the long-chained lipids extracted from grain sorghum kernels were policosanols $(\approx 40 \%)$, aldehydes $(\approx 50 \%)$, and acids $(\approx 4 \%)$ (Fig. 1, Table II). That is, policosanols comprised $\approx 0.08 \%(\mathrm{w} / \mathrm{w}, \mathrm{db})$ of grain sorghum kernels. Hydrocarbons and triacylglycerols were $\leq 1 \%$ in the long-chained lipids from grain sorghum kernels.

The Bianchi group studied plant waxes extensively and prepared two reports regarding the composition of wax from grain sorghum (Bianchi et al 1979; Avato et al 1990). The first reported that surface wax of dried grain sorghum contained $34 \%$ alcohols, $32 \%$ aldehydes, $24 \%$ acids, $4 \%$ esters (contaminated with unidentified materials), and $1 \%$ alkanes. The second reported that wax contained $32 \%$ alcohols, $21 \%$ aldehydes, $27 \%$ acids, $13 \%$ esters, and $7 \%$ hydrocarbons. To our knowledge, only those manuscripts and the two by Hwang et al $(2002 a, b)$ reported that sorghum wax contained a large amount of aldehydes. Furthermore, both studies by the Bianchi group and this study found the major components of long-chained lipids extracted from grain sorghum were alcohols, aldehydes, and acids. The differences in levels of longchained lipid components in the studies of the Bianchi group from this study may have resulted from the Bianchi group using different sorghum types (Sorghum bicolor SD-102 and Sorghum bicolor L. cv. Martin B grown in Italy), a different wax extraction method (using benzene as extraction solvent), and a different analytical method (separating the wax components using column chromatography, evaporating the solvent, and weighing the dried materials).

Policosanol levels in the long-chained lipids extracted from sorghum DDG were more than twice as great as aldehyde levels (Fig. 1, Table II). Comparing similar levels in grain sorghum kernels, aldehydes were more plentiful than policosanols. The long-chained lipids extracted from sorghum DDG contained a large amount of triacylglycerols $(13 \%)$ and wax esters and steryl esters $(14 \%)$ compared with grain sorghum kernels $(0.3-0.4 \%$ and $0 \%$, respectively). Triacylglycerols and wax esters and steryl esters likely reside in the interior of whole kernels and are released during ethanol production processes. Therefore, the glycerols and esters can be extracted more easily from DDG than from intact kernels.

The yield difference between rinsed and nonrinsed DDG lipid samples discussed above was mainly due to the presence or lack of triacylglycerols, which decreased from $13 \%$ in the nonrinsed sample to $0.7 \%$ in the rinsed sample. It also implies that the triacylglycerols extracted from DDG were precipitated in hexane at a freezing temperature and dissolved in hexane at room temperature. Hwang et al (2002b) were not able to distinguish between wax esters and steryl esters using HPLC.

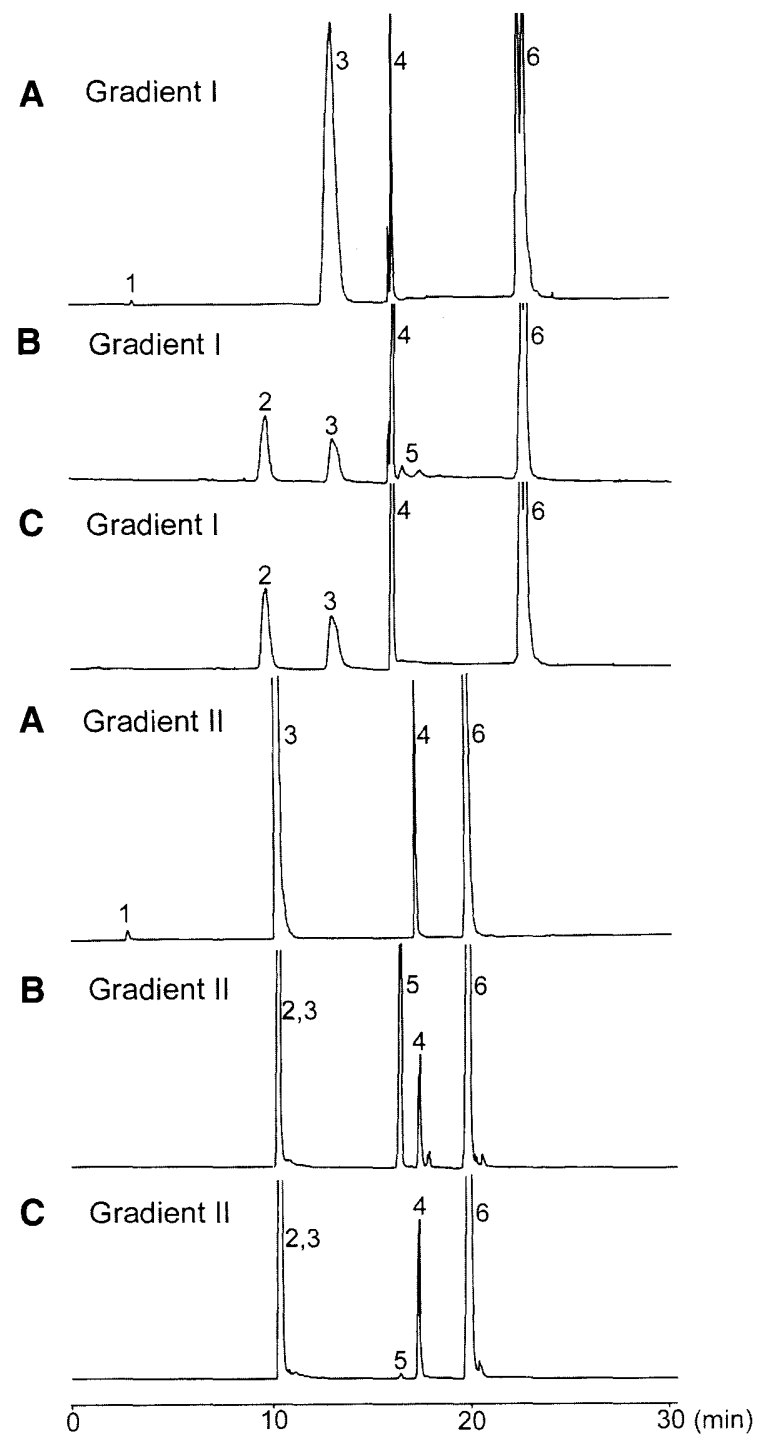

Fig. 1. HPLC of long-chained lipids extracted from grain sorghum Golden Harvest H512 1999 (A); dried distillers grains (DDG), filtered precipitate not rinsed (B); and DDG, filtered precipitate rinsed (C). (1) Hydrocarbons; (2) wax esters and steryl esters; (3) aldehydes; (4) acids; (5) triacylglycerols; and (6) policosanols.

TABLE II

Long-Chained Lipids Extracted from Grain Sorghum Kernels and Sorghum Dried Distillers Grains (DDG) a,b

\begin{tabular}{|c|c|c|c|c|c|c|c|}
\hline & \multirow{2}{*}{$\begin{array}{c}\text { Yield } \\
(\%, w / w, d b) \\
\end{array}$} & \multicolumn{6}{|c|}{ Composition of Long-Chained Lipids ${ }^{\mathbf{c}}(\%, \mathrm{w} / \mathrm{w})$} \\
\hline & & Policosanols & Aldehydes & Acids & HC & TG & WE \& SE \\
\hline \multicolumn{8}{|l|}{ Sorghum kernels } \\
\hline Golden Harvest H512 (1999) & $0.23(0.03)$ & $43.9(0.6)$ & $48.4(0.9)$ & $4.8(0.2)$ & $0.6(0.1)$ & $0.4(0.0)$ & $\ldots$ \\
\hline Ethanol-extracted & $0.24(0.02)$ & $37.1(1.2)$ & $55.0(1.5)$ & $4.4(0.6)$ & $1.1(0.1)$ & $0.3(0.1)$ & $\cdots$ \\
\hline Warner W902W FG (1999) & $0.20(0.00)$ & $38.2(1.0)$ & $54.6(1.3)$ & $4.1(0.4)$ & $0.6(0.1)$ & $0.4(0.0)$ & $\cdots$ \\
\hline Producers (1999) & $0.20(0.01)$ & $39.7(5.0)$ & $53.5(5.5)$ & $3.9(0.5)$ & $0.5(0.0)$ & $0.3(0.0)$ & .. \\
\hline PH77FG (2000) & $0.30(0.00)$ & $40.0(0.6)$ & $53.3(0.9)$ & $3.9(0.2)$ & $0.5(0.1)$ & $0.3(0.0)$ & $\cdots$ \\
\hline Warner W902W FG (2000) & $0.28(0.00)$ & $39.6(2.5)$ & $53.1(2.8)$ & $4.4(0.2)$ & $0.6(0.0)$ & $0.3(0.0)$ & $\cdots$ \\
\hline \multicolumn{8}{|l|}{ DDG } \\
\hline Filtered precipitate not rinsed & $0.59(0.04)$ & $46.3(0.8)$ & $18.4(0.5)$ & $6.3(0.3)$ & $\cdots$ & $12.6(0.8)$ & $14.4(0.9)$ \\
\hline Filtered precipitate rinsed with hexane & $0.48(0.06)$ & $52.2(0.9)$ & $22.8(0.5)$ & $6.4(0.1)$ & $\cdots$ & $0.7(0.2)$ & $17.4(1.0)$ \\
\hline
\end{tabular}

${ }^{a}$ Extraction solvent was hexane, unless otherwise specified.

${ }^{\mathrm{b}}$ Mean values with standard deviations (in parentheses) of three replicates.

${ }^{c} \mathrm{HC}$, hydrocarbons; TG, triacylglycerols; WE \& SE, wax esters and steryl esters. 
TABLE III

Policosanols in Grain Sorghum Kernels and Sorghum Dried Distillers Grains (DDG) (\%, w/w) ${ }^{\mathrm{a}}$

\begin{tabular}{|c|c|c|c|c|c|c|c|c|c|}
\hline & \multicolumn{9}{|c|}{ Alcohols } \\
\hline & 22:0 & 24:0 & 25:0 & 26:0 & 27:0 & 28:0 & 29:0 & 30:0 & $32: 0$ \\
\hline \multicolumn{10}{|l|}{ Sorghum kernels } \\
\hline Golden Harvest H512 (1999) & $0.4(0.1)$ & $3.1(0.2)$ & $0.1(0.1)$ & $8.2(0.3)$ & $0.8(0.1)$ & $43.7(0.4)$ & $1.3(0.0)$ & $40.9(0.7)$ & $1.5(0.1)$ \\
\hline Warner W902W FG (1999) & $0.5(0.1)$ & $2.9(0.2)$ & $\cdots$ & $7.3(0.2)$ & $0.8(0.0)$ & $43.0(0.4)$ & $1.5(0.0)$ & $40.7(0.6)$ & $3.5(0.2)$ \\
\hline \multicolumn{10}{|l|}{ DDG } \\
\hline Filtered precipitate not rinsed & $\cdots$ & $1.0(0.3)$ & $\cdots$ & $5.2(0.4)$ & $1.0(0.2)$ & $45.7(0.8)$ & $0.7(0.1)$ & $44.8(0.3)$ & $1.7(0.5)$ \\
\hline
\end{tabular}

${ }^{a}$ Mean values with standard deviations (in parentheses) of three replicates.

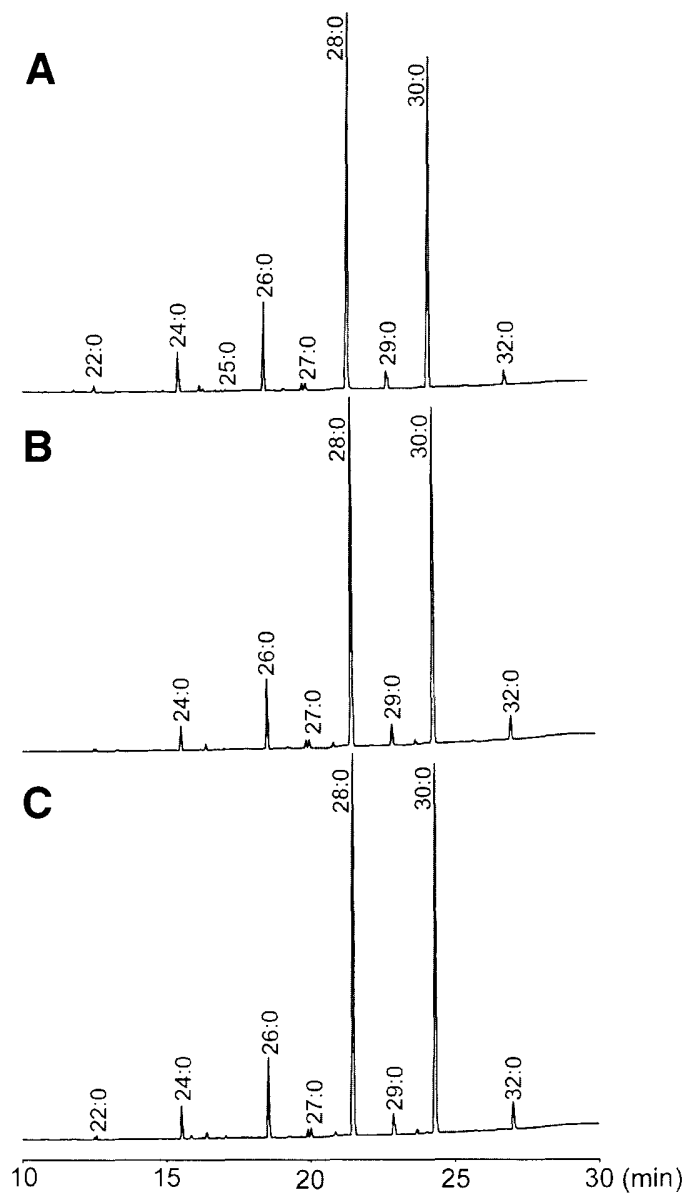

Fig. 2. Gas chromatography of policosanols in grain sorghum (Golden Harvest H512 1999) (A); DDG-filtered precipitate not rinsed (B); and DDG-filtered precipitate rinsed $(\mathbf{C})$.

Pink coloration (steryl esters, if not stanyl esters, turn pink on TLC plates during charring when $10 \%$ cupric sulfate in $8 \%$ phosphoric acid is used as a visualization solution [Bitman and Wood 1982]) was barely noticeable on TLC bands corresponding to wax esters and steryl esters of the long-chained lipids extracted from sorghum DDG. Therefore, existence of a detectable amount of steryl esters may have been remotely possible, but the presence of stanyl esters could not be excluded.

Further analyses are needed to identify and quantify wax esters and steryl esters in long-chained lipids extracted from sorghum DDG.

Octacosanol (28:0) and triacontanol (30:0) comprised $>80 \%$ of policosanols in grain sorghum kernels and DDG (Fig. 2, Table III). Hexacosanol (26:0), dotriacontanol (32:0), lignoceryl alcohol (24:0), and nonacosanol (29:0) followed in descending order of concentration. These results were consistent with the reports by Bianchi et al (1979) and Avato et al (1990).
Rice germ, wheat germ, beeswax, and sugar cane are major sources of commercial policosanols. Triacontanol, octacosanol, hexacosanol, and lignoceryl alcohol are major components in commercially available policosanols. Kawanishi et al (1991) reported the compositions of policosanols in oils and waxes of various nuts, seeds, fruits, and cereals. They reported policosanols extracted from rice germ were composed of $51 \%$ triacontanol, $35 \%$ octacosanol, and $14 \%$ hexacosanol. Policosanols from wheat germ contained $62 \%$ triacontanol, $21 \%$ octacosanol, and $18 \%$ hexacosanol.

Comparing the contents of octacosanol in rice germ (5.2 ppm) and wheat germ (2.6 ppm) reported by Kawanishi et al (1991), grain sorghum kernels ( $\approx 800 \mathrm{ppm}$ of policosanols) and DDG $(\approx 2,500$ $\mathrm{ppm}$ ) are sources of abundant policosanols. Commercial policosanols are produced mostly through saponification of wax esters in cereal germ waxes. No saponification process is needed for policosanols recovered from grain sorghum kernels and DDG due to the presence of free forms of the policosanols. Simple comparison of commercial policosanols to the free policosanol contents of grain sorghum kernels and DDG may not be proper. Additionally, no cereal grain is comparable with grain sorghum in terms of wax (or long-chained lipid) yield.

\section{CONCLUSIONS}

Two major benefits of utilizing policosanols present in grain sorghum as a commercial source of policosanols can be envisioned. One benefit relates to the abundance of policosanols in grain sorghum. The other benefit comes from not needing a saponification process, which is a method for producing policosanols from wax esters. Moreover, obtaining policosanols from sorghum DDG adds value to an underutilized by-product. Lipids in DDG are readily extractable due to greater exposure of the inner part of the grain sorghum kernels to solvent because of grinding, fermentation, and distillation processes. High yield of long-chained lipids and high level of policosanols in sorghum DDG compared with grain sorghum kernels and the similarity of policosanol composition between DDG and grain sorghum kernels can be additional benefits of the using of sorghum DDG for policosanol production.

\section{ACKNOWLEDGMENTS}

A contribution of the University of Nebraska Agricultural Research Division, Lincoln, NE. Journal Series No. 14045. This research was supported in part by funds provided by Chonbuk National University, Korea and through the Hatch Act.

\section{LITERATURE CITED}

Arruzazabala, M. L., Carbajal, D., Mas, R., Molina, V., Valdes, S., and Laguna, A. 1994. Cholesterol-lowering effects of policosanol in rabbits. Biol. Res. 27:205-208.

Arruzazabala, M. L., Valdes, S., Mas, R., Fernandez, L., and Carbajal, D. 1996. Effect of policosanol successive dose increases on platelet aggregation in healthy volunteers. Pharmacol. Res. 34:181-185.

Avato, P., Bianchi, G., and Murelli, C. 1990. Aliphatic and cyclic lipid 
components of sorghum plant organs. Phytochemistry 29:1073-1078.

Bianchi, G., Avato, P., and Mariani, G. 1979. Composition of surface wax from sorghum grain. Cereal Chem. 56:491-492.

Bitman, J., and Wood, D. L. 1982. An improved copper reagent for quantitative densitometric thin-layer chromatography of lipids. J. Liq. Chromatogr. 5:1155-1162.

Bunger, W. B., and Kummerow, F. A. 1951. A comparison of several methods for the separation of unsaponifiable material from carnauba and grain sorghum waxes. J. AOCS 28:121-123.

Cannon, C., and Kummerow, F. A. 1957. A comparison of plant and grain wax from two varieties of sorghum. J. AOCS 34:519-520.

Dalton, J. L., and Mitchell, H. L. 1959. Fractionation of grain sorghum wax. Agric. Food Chem. 7:570-573.

González-Canavaciolo, V. L., and Magraner-Hernández, J. 1999. Validation of a gas chromatographic method for determining fatty alcohols that compose policosanol in five-milligram film-coated tablets. J. AOAC Int. 82:834-839.

Gouni-Berthold, I., and Berthold, H. K. 2002. Policosanol: Clinical pharmacology and therapeutic significance of a new lipid-lowering agent. Am. Heart J. 143:356-365.

Hwang, K. T., Cuppett, S. L., Weller, C. L., Hanna, M. A., and Shoemaker, R. K. 2002a. Aldehydes in grain sorghum wax. J. AOCS 79: 529-533.

Hwang, K. T., Cuppett, S. L., Weller, C. L., and Hanna, M. A. 2002b. HPLC of grain sorghum wax classes highlighting separation of aldehydes from wax esters and steryl esters. J. Separation Sci. 25:619-623.
Kabir, Y., and Kimura, S. 1995. Tissue distribution of (8-14C)-octacosanol in liver and muscle of rats after serial administration. Ann. Nutr. Metab. 39:279-284

Kato, S., Karino, K.-I., Hasegawa, S., Nagasaki, A., Eguchi, M., Ichinose, T., Tago, K., Okumori, H., Hamatani, K., Takahashi, M., Ogasawara, J., Masushige, S., and Hasegawa, T. 1995. Octacosanol affects lipid metabolism in rats fed on a high-fat diet. Brit. J. Nutr. 73:433-441.

Kawanishi, K., Aoki, K., Hashimoto, Y., and Matsunobu, A. 1991. Free primary alcohols in oils and waxes from germs, kernels and other components of nuts, seeds, fruits and cereals. J. AOCS 68:869-872

Nordbäck, J., and Lundberg, E. 1999. High resolution separation of nonpolar lipid classes by HPLC-ELSD using alumina as stationary phase. J. High Res. Chromatogr. 22:483-486.

Seitz, L. M. 1977. Composition of sorghum grain wax. Cereal Foods World 22:472.

Stewart, M. E., and Downing, D. T. 1981. Separation of wax esters from steryl esters by chromatography on magnesium hydroxide. Lipids 16:355-359.

Stüsser, R., Batista, J., Padrón, R., Sosa, F., and Pereztol, O. 1998. Longterm therapy with octacosanol improves treadmill exercise-ECG testing performance of coronary heart disease patients. Int. J. Clin. Pharm. Therapy 36:469-473.

Weller, C. L., Cuppett, S. L., Hua, L. C., Lochte-Watson, K. R., Gaudoin, C., Arrault, J., Hubbard, C., and Mua, J. P. 2000. Solvent influence on yield and fractions of grain sorghum wax. Paper No. 00-6134. ASAE: St. Joseph, MI.

[Received March 21, 2003. Accepted September 25, 2003.] 